\title{
O ENSINO DE LÍNGUA LATINA NA UNIVERSIDADE BRASILEIRA E SUA CONTRIBUIÇÃO PARA A FORMAÇÃO DO GRADUANDO EM LETRAS ${ }^{1}$
}

LATIN LANGUAGE TEACHING IN BRAZILIAN UNIVERSITIES AND ITS CONTRIBUTION TO THE FORMATION OF LANGUAGE AND LITERATURE MAJORS

Leni Ribeiro Leite ${ }^{2}$

Marihá Barbosa e Castro ${ }^{3}$

Resumo: A partir de um referencial teórico sobre o ensino de latim no Brasil e das respostas a um questionário realizado com professores de língua e literatura latina atuantes em várias universidades públicas brasileiras, a pesquisa da qual este trabalho é uma primeira apresentação pretende, por um lado, estabelecer um panorama do ensino de língua latina no Brasil atualmente e, por outro, esboçar um modelo de ensino de língua latina desejado pelos mesmos profissionais, tendo como objeto não só a metodologia como também os objetivos e o conteúdo abordado. Pretende-se, com isso, observar como a universidade pública brasileira pensa atualmente a contribuição do ensino de língua, cultura e literatura latina para a formação dos licenciados em Letras modernas que não se aprofundarão na área de Estudos Clássicos, parte significativa do alunado nas salas de aula de latim.

Palavras-chave: Ensino de Latim, Universidade Brasileira, Formação de professores.

Abstract: Based on previous works on Latin teaching in Brazil and on the answers to a questionnaire by Latin Language and Literature professors in many universities in Brazil, the research to which this paper is a first presentation aims at, on one hand, offering a picture of the teaching of Latin being currently carried out in the country, and, on the other, outlining a model of teaching desired by the same professionals, looking not only at the methodology applied but also at the goals and content of their teaching practices. By doing that, we intend to view how the teachers conceive the role played by the

1 Esta pesquisa conta com o apoio da Fundação de Amparo à Pesquisa do Espírito Santo (FAPES).

2 Professora da Universidade Federal do Espírito Santo.

3 Discente do Programa de Pós-Graduação em Letras da Universidade Federal do Espírito Santo. 
area of Latin Language, Literature and Culture in the formation of students who major in Modern Languages, and who will not specialize in Classics, a significative part of the current Latin classrooms.

Keywords: Latin teaching, Brazilian universities, teacher formation.

Para observar qual o lugar ocupado pelo latim, atualmente, nos currículos das Licenciaturas e Bacharelados em Letras das universidades públicas brasileiras, procurando, simultaneamente, compreender (1) de que maneira o ensino do latim ocorre, (2) como a disciplina pode contribuir para a formação do aluno de Letras e (3) quais as concepções dos professores sobre este papel e como cumpri-lo, é necessário começar compreendendo a trajetória do próprio ensino do latim no Brasil através dos séculos.

Apesar do esfacelamento e dissolução do Império Romano do Ocidente, o latim e a cultura clássica gozaram, por muito tempo, de privilegiado estatuto no mundo intelectual, sendo considerados basilares para a formação do homem erudito. Até o século XVIII, o latim se configurava como uma língua de cultura: a comunicação dos pensadores das mais diferentes localidades era possível através da veiculação de textos escritos em latim, língua dominada por grande parte dos intelectuais. Antes e depois desse período, foi a língua oficial da Igreja Católica, o que contribuiu com a manutenção de seu prestígio e difusão. É um fato, portanto, que apesar de não mais haver falantes nativos de latim, o idioma permaneceu em constante uso pelos religiosos, filósofos, cientistas e letrados ${ }^{4}$.

Expor os motivos que levaram as letras clássicas e especialmente o latim a ocuparem tão importante papel no cenário intelectual, cultural e literário do mundo ocidental durante tão longo período - considerando que apenas na segunda metade do século XX os estudos clássicos tiveram seu decisivo declínio - é uma tarefa extensa que nos faria perder de vista o principal objeto de análise deste trabalho ${ }^{5}$ : o ensino de latim nas universidades públicas brasileiras no século XXI. Para atingir este fim, deteremo-nos brevemente na exposição da trajetória do latim nos currículos da educação brasileira, sobretudo, da análise das diversas mudanças nos currículos dos ensinos secundário e superior, até a supressão do latim como disciplina obrigatória no ensino básico a partir da LDB de 1961.

4 Para um panorama detalhado da permanência e uso do latim nos períodos medieval e renascentista, cf. OSTLER (2007: 190-259); SOLODOW (2010: 31-55).

5 Para esse importante porém longo excurso, recomendamos a leitura de IJSEWIJN (1990) e IJSEWIJN \& SACRE (1998). 
A história do ensino de latim, no Brasil, começa com a fundação das primeiras escolas e iniciativas educacionais dos colonizadores: a chegada dos padres da Companhia de Jesus, em 1549, na expedição de Tomé de Souza, marca o início da história da educação brasileira. Já nos primeiros quinze dias após o desembarque, os Jesuítas criaram a primeira escola "de ler e escrever" da colônia. Mais tarde, em 1556, inauguraram o Colégio de Todos os Santos, em Salvador. Ao longo dos 210 anos em que gerenciaram a educação da colônia brasileira, fundaram diversas escolas, oferecendo não só o ensino elementar, mas também o de nível superior (SHIGUNOV NETO; MACIEL: 2008, 174-176). A Companhia de Jesus, criada em 1539 por Inácio de Loyola, surgira durante o período em que a Igreja Católica empenhara esforços para realizar a Contrarreforma, buscando responder aos então recentes eventos de dissidência, perda de hegemonia e de domínio religioso em algumas regiões da Europa por consequência da Reforma Protestante. A ordem fora reconhecida em 1540 pelo papa Paulo III e possuía a princípio poucos membros - no máximo 60, de acordo com a primeira legislação. Porém, seu crescimento espantoso fizera com que essa limitação fosse revogada: em poucos anos, a Companhia de Jesus tinha representantes em diversas regiões do mundo, inclusive nas colônias espanholas e portuguesas no continente americano, onde procuraram realizar as missões de evangelização e propagação da fé católica. (SHIGUNOV NETO; MACIEL: 2008, 171)

Acredita-se que a catequização dos índios se configurava como um dos principais objetivos dos jesuítas no Brasil. Para Gislene Raymundo (1998), a Companhia de Jesus servia mutuamente aos interesses da Coroa Portuguesa e do Papado, já que ambos pretendiam "expandir o mundo, defender as novas fronteiras, somar forças, integrar interesses leigos e cristãos, organizar o trabalho no Novo Mundo pela força da unidade lei-rei-fé" (RAYMUNDO, 1998: 43). Neste trabalho, porém, as razões políticas da atuação dos jesuítas como professores e catequizadores no Brasil não constituíram nosso foco: interessou-nos, sobretudo, a dimensão prática dessa atuação docente.

Os jesuítas daquele período nos legaram, como registro seja de sua prática, seja dos ideais desta prática, as páginas da Ratio Studiorum, método de ensino que estabelecia a organização e administração do sistema educacional e o currículo a ser seguido pelos padres professores da Ordem de Jesus. Segundo Luis Freire (2008), a Ratio Studiorum surgiu, pois "diante do grande número das escolas e da consequente necessidade de unificar os procedimentos que adotavam, os inacianos criaram a Ratio Studiorum, para regulamentar todo o seu ensino" (FREIRE, 2008: 180). O autor define

Organon, Porto Alegre, v. 29, n. 56, p. 223-244, jan/jun. 2014. 
o método pedagógico dos jesuítas como um ensino tradicional e literário, que valorizava a educação física e intelectual no curso primário, e a educação das Letras ministrada através da leitura dos autores clássicos no ensino médio. Para Freire, "o método de ensino utilizado pelos jesuítas era principalmente expositivo, livresco, com pouco ou nenhum sentido prático" (FREIRE, 2008: 181). Além disso, o autor considera que o cultivo da língua e das Humanidades entrava em contraste com o ensino muitas vezes desajustado e inevitável do latim.

A Ratio Studiorum procura unificar o método da Companhia e, por isso, prescreve detalhadamente de que maneira as aulas de cada disciplina devem ser ministradas nos vários níveis do ensino, indicando também a postura e abordagem adequadas para os professores e coordenadores dos colégios da Ordem. De certa forma, aquele documento, promulgado pelo alto comando jesuíta em 8 de janeiro de 1599, se aproxima dos documentos hoje norteadores da educação básica brasileira, como os PCNs: não no que diz respeito ao conteúdo e preceitos educacionais defendidos, mas na medida em que procura instrumentalizar os docentes a respeito de suas práticas em sala de aula, buscando manter a uniformidade do projeto em toda a sua extensão. Isso demonstra o quanto estavam preocupados os Jesuítas em construir um projeto educacional que fosse realmente efetivo e que cumprisse os objetivos pedagógicos da Companhia de Jesus.

Não é, portanto, difícil observar que, no que pesem quaisquer discordâncias que tenhamos acerca dos métodos e objetivos do modelo educacional jesuíta, seu projeto pedagógico possuía o mérito de ser organizado e sistemático, qualidades que fizeram com que os inacianos controlassem a educação secundária de modo quase absoluto durante dois séculos. A formação acadêmica do homem ocidental durante os séculos XVI e XVII era amplamente definida pelo projeto educacional jesuíta, que foi responsável, também, por instruir as camadas menos favorecidas da população europeia.

Os estudos clássicos e o ensino do latim eram igualmente definidos pelo projeto pedagógico postulado pela Ratio Studiorum. Essas disciplinas eram ministradas de acordo com uma leitura do mundo clássico profundamente ligada ao cristianismo. Para exemplificar de que modo essa característica influenciava o ensino de língua e literatura latina, observemos um trecho da Ratio Studiorum em que se fala sobre a proibição de livros inconvenientes:

que de modo algum se sirvam os nossos, nas aulas, de livros de poetas ou outros, que possam ser prejudiciais à honestidade e aos bons costumes, enquanto não forem expurgados 
dos fatos e palavras inconvenientes; e se de todo não puderem ser expurgados, como Terêncio, é preferível que não se leiam para que a natureza do contendo não ofenda a pureza da alma (FRANCA: 1952, 6).

Terêncio, autor de comédias romanas, era colocado entre os que deveriam ser evitados, pois era considerado prejudicial à honestidade e aos bons costumes devido a seu conteúdo. Entendemos que, ao enfatizar a proibição de livros de poetas ou outros, o documento aponta para uma tendência em afastar a poesia da sala de aula, dando preferência a outras formas literárias. Assim como tal afirmação pode se aplicar a poetas contemporâneos ao documento, é presumível - ainda mais quando o único autor citado é romano - que essa recomendação fosse a respeito, sobretudo, de autores clássicos que não confirmavam, em suas obras, as virtudes e valores romanos que foram importados para a doutrina cristã. Esses valores, entretanto, são observados nos discursos de Cícero, por exemplo. Quando sugeridas as leituras de Ovídio, Catulo, Virgílio, Tibulo e Propércio, fica clara a preocupação em selecionar os trechos que não sejam nocivos à moralidade, expurgando os poemas antes de levá-los às salas de aula:

Para conhecimento da língua, que consiste principalmente na propriedade e riqueza das palavras, explique-se, nas lições quotidianas [...] dos poetas, principalmente Virgílio com exceção de algumas éclogas e do 4o. livro da Eneida, odes seletas de Horácio e também elegias, epigramas e outras composições de poetas ilustres, contanto que expurgados de qualquer inconveniência de expressão. (FRANCA: 1952, 38). [grifos nossos]

Quanto às leituras, poderão explicar-se no primeiro semestre dos prosadores, as cartas mais importantes de Cícero [...]; dos poetas no primeiro semestre algumas elegias ou epístolas de Ovídio, escolhidas e expurgadas, no segundo, trechos, também escolhidos e expurgados, de Catulo, Tibulo, Propércio e das Éclogas de Virgílio, ou ainda, do mesmo Virgílio, os livros mais fáceis como o 40. das Geórgicas, o 5o. e o 7o. da Eneida (FRANCA: 1952, 41). [grifos nossos]

O nome de Cícero, entre os autores romanos, é o mais citado da $R a$ tio Studiorum (35 vezes), sendo amplamente recomendada a sua leitura, análise e imitação para as mais variadas finalidades educativas. Os trechos 
a seguir foram retirados do documento e demonstram como Cícero era valorizado por este projeto educacional:

O tempo será dividido do seguinte modo. Na primeira hora da manhã recite-se o trecho decorado de Cícero e da arte métrica, tomado pelos decuriões (...).

Enquanto corrige os trabalhos escritos pode passar algum dos exercícios seguintes: colher frases dos trechos explicados e variá-las de muitas maneiras; reconstituir um período de Cícero que haja sido desarticulado; fazer versos, passar uma poesia de uma para outra forma; imitar um trecho, escrever em grego (ou em vernáculo) e outros semelhantes (FRANCA: 1952, 39).

Quanto às leituras, poderão explicar-se no primeiro semestre dos prosadores, as cartas mais importantes de Cícero aos parentes, a Ático, ao irmão Quinto (...).

Na segunda hora matutina, repetição breve da última lição de Cícero, explicação por meia hora da nova, que será logo objeto de interrogação, por último, ditado do tema (FRANCA: 1952, 41).

Às vezes poderá mandar-se aos alunos que transcrevam alguma versão curta de Cícero, ou alguma expressão para aplicação das regras de sintaxe, ou a própria lição dos elementos de grego que deverão estudar ou outros trabalhos semelhantes (FRANCA: 1952, 45).

Quanto às regras, ainda que se possam procurar e observar em todas as fontes, não se deve, contudo, explicar, na preleção quotidiana, senão nos livros retóricos de Cícero, na Retórica de Aristóteles, e, se parecer conveniente, também na sua Poética. No que concerne ao estilo, ainda que se devam percorrer os melhores historiadores e poetas, deverá ser formado quase exclusivamente em Cícero; para esse fim se adaptam perfeitamente todos os seus livros, mas as orações deverão ser só explicadas a fim de que nelas se vejam a aplicação dos preceitos da oratória (FRANCA: 1952, 3536).

Observam-se, portanto, dois aspectos importantes da educação ministrada pelos jesuítas: (1) há a clara preocupação em incluir a cultura clássica e, principalmente, o ensino de latim em todos os níveis do ensino, mas (2) essa inclusão se faz de modo faccioso, uma vez que, quase sempre, os textos antigos eram escolhidos e apresentados para os alunos de acordo com critérios da moralidade cristã; os autores antigos eram utilizados 
para corroborar os ideais de virtude e dignidade humana valorizados pela Companhia de Jesus e pela Igreja Católica. Importa lembrar que, a esta altura, o latim já se havia desprendido do mundo clássico: era comum a produção de poemas cristãos, filosofia e teologia nesse idioma; os autos, os cânticos e os sermões eram tradicionalmente escritos em latim; a Bíblia Vulgata era a versão oficial da palavra de Deus e a comunicação interna da Igreja era feita através do latim, que já não mais possuía falantes nativos. $\mathrm{O}$ latim, portanto, não era mais a língua que representava o povo, a cultura e a literatura romana: seus diversos usos fizeram com que todos os demais povos europeus dele se apropriassem e utilizassem como sua própria língua, e isso se vê refletido no currículo jesuítico, que usa o latim não só na recuperação dos elementos da cultura clássica, mas como veículo de expressão do pensamento cristão e das diversas culturas europeias. Sobre isso, Alexandre Shigunov Neto e Lizete Maciel informam que

O método educacional jesuítico foi fortemente influenciado pela orientação filosófica das teorias de Aristóteles e de São Tomás de Aquino, pelo Movimento da Renascença e por extensão, pela cultura europeia. Apresentava como peculiaridades a centralização e o autoritarismo da metodologia, a orientação universalista, a formação humanista e literária e a utilização da música (SHIGUNOV NETO; MACIEL: 2008, 180).

Embora possamos analisar a apropriação que os jesuítas fizeram da cultura e da literatura clássica para construir seu currículo como tendenciosa e programática, a educação jesuítica se caracterizava pela adoção de uma formação de caráter humanista, ou seja, que considerava como mais importantes a dignidade, a cultura e a arte, colocando em segundo plano o pragmatismo do ensino, não se preocupando em formar alunos para o trabalho.

A educação jesuítica, pautada no Humanismo, vigorou durante dois séculos no Brasil e em muitas outras partes do mundo, sendo considerada de excelência, pois o rigor da Companhia de Jesus garantia o bom funcionamento das escolas. Entretanto, o poder acumulado pela Ordem de Jesus em dois séculos passou a ser visto como ameaça à soberania de muitos países e até mesmo da própria Igreja. Os jesuítas sofreram, ao longo do século XVIII, diversas retaliações: foram expulsos da França por Luís XV em 1764; na Espanha, Carlos III decretou a prisão de todos os jesuítas em 1767; em Portugal e suas colônias não foi diferente: os jesuítas foram

Organon, Porto Alegre, v. 29, n. 56, p. 223-244, jan/jun. 2014. 
expulsos pelo ministro da Fazenda do rei D. José I, o Marquês de Pombal que, através do Alvará de 18 de junho de 1759, oficializou o fim da educação ministrada pela Companhia de Jesus em todas as regiões do império, expulsando-os das terras portuguesas. Em 1773, o Papa Clemente XIV decretou oficialmente a supressão da Companhia de Jesus ${ }^{6}$.

A expulsão dos jesuítas foi muito significativa para a educação brasileira: desde a sua chegada à colônia, os padres inacianos tinham construído diversas escolas e sido responsáveis por quase a totalidade das instituições de ensino. Ao expulsar os jesuítas, o Marquês de Pombal baniu, praticamente, todos os professores da colônia, que possuía pouquíssimas alternativas paralelas aos jesuítas até então. A transformação curricular idealizada pelo ministro não foi de fato posta em prática, ficando no plano do ideal por bastante tempo até começar a ser vagamente aplicada. O que ocorreu não foi um processo de adaptação ou reforma do currículo: não houve nenhum traço de continuidade entre o ensino praticado pelos jesuítas e aquele idealizado por Marquês de Pombal, mas sim uma ruptura que deixou muitos estudantes e professores (os poucos não jesuítas e aqueles que preferiram abandonar a Companhia de Jesus) confusos a respeito de seus objetivos e práticas em sala de aula.

Pombal, amplamente influenciado pelos ideais Iluministas, pretendia substituir a metodologia eclesiástica de ensino, empregada até então, por uma metodologia laica (MACIEL; SHIGUNOV NETO: 2006, 470). Procurando, portanto, reparar o ensino, o rei D. José instaurou, através do Alvará Régio de 1759, o sistema de aulas régias, de modo que fosse possível não só

lutar contra a decadência dos estudos, 'mas restituir-lhes aquele antecedente lustre que fez os portugueses tão conhecidos na república das letras'. Ainda segundo o Alvará, o ensino jesuítico havia interrompido a tradição do humanismo quinhentista, que agora precisava ser restaurado (ALMEIDA: 2001, 73).

A principal obra do período pombalino foi $O$ verdadeiro método de estudar (1746), de Luís Antonio Verney, cujas proposições guiaram as reformas do ensino. Verney postulava o ensino de literatura através do português, do latim, da retórica e da poética. Embora possa parecer que a proposta de Verney pouco se distanciasse do currículo jesuíta, essas disciplinas, ainda que permanecessem as mesmas, aparecem de modo completamente diverso.

6 Para uma história mais completa da Companhia de Jesus no Brasil e no mundo, v. PEDRO (2008) e BANGERT (1985). 
O autor tece várias críticas ao modo ineficaz como os jesuítas ministravam as aulas de latim, gastando muito tempo na memorização de regras gramaticais, mas dedicando pouco tempo à leitura e exercícios de oralidade que poderiam ajudar os alunos a dominar melhor o idioma. Verney acreditava que o método jesuíta tinha como resultado alunos que não conseguiam, em suma, ler o latim, e propunha reformas para os estudos menores (educação secundária) que estivessem alicerçadas no estudo da Antiguidade Clássica, de forma que os estudantes se percebessem unidos à tradição e à cultura clássicas. Verney defendia que somente através dos textos dos grandes autores latinos os estudantes poderiam compreender e conhecer a cultura clássica e, para isso, o estudo do latim era necessário. Ao confrontarmos o ensino de latim praticado pelos jesuítas e o proposto por Verney, percebemos que a principal diferença está no modo como cada uma dessas orientações pedagógicas enxergava o latim:

O latim dos jesuítas era ensinado e empregado como uma língua universal, viva e falada no seio da Igreja. Já o ensino da língua latina proposto pela reforma terá um caráter totalmente diverso, na medida em que o latim será encarado como língua morta, deixando de ser uma língua falada para ser valorizada como herança. E, por isso, o ensino do latim impõe-se, obrigatoriamente, na língua materna, com a proibição, pelo menos nos primeiros anos, de se falar latim nas aulas (ALMEIDA: 2001, 76).

Anita Almeida observa, ainda, que o método de Verney estava alicerçado no princípio lockiano de utilidade da cultura. Assim, "os estudos superiores deveriam ser ajustados às necessidades culturais de Portugal, e os estudos menores à sua função de preparatório para a universidade, para que resultasse em 'uma maior eficiência ou utilidade, dos homens formados pela universidade" (ALMEIDA: 2001, 74). A retórica, por exemplo, afastando-se da tradição jesuítica que tendia a ensiná-la como um compêndio de tropos e figuras - que, segundo Verney, constituía a mínima parte da disciplina, ou a que merecia menor consideração - se configuraria como uma importante arma de batalha a favor da construção das novas representações do reino português, que queria deixar a velha representação de um reino cristão em favor de uma outra que o considerasse como uma nação "europeia, polida e civilizada".

Entretanto, por mais sedutoras que possam parecer as ideias de Verney, não houve a concretização de tais ideais. Ao contrário, segundo Shigunov Neto \& Maciel,

Organon, Porto Alegre, v. 29, n. 56, p. 223-244, jan/jun. 2014. 
A reforma de ensino pombalina pode ser avaliada como sendo bastante desastrosa para a Educação brasileira e, também, em certa medida para a Educação em Portugal, pois destruiu uma organização educacional já consolidada e com resultados, ainda que discutíveis e contestáveis, e não implementou uma reforma que garantisse um novo sistema educacional (MACIEL; SHIGUNOV NETO: 2006, 475).

As propostas da reforma pombalina para a educação não vingaram, pois provocaram a desorganização e a decadência da educação na colônia, criando um parêntese de quase meio século em que se podem observar diversas tentativas frustradas de aplicar, na prática, aquilo que havia sido concebido teoricamente pelo Alvará de 18 de junho de 1759. A expulsão dos jesuítas, portanto, muito longe de resolver as questões do currículo educacional - se considerarmos que a abordagem dos jesuítas estava sendo bastante criticada em um momento em que os ideais iluministas se alastravam - criou uma situação caótica em que uma educação regular e consolidada foi substituída pela ausência de um sistema educacional. A marca, portanto, das reformas pombalinas para o ensino, no Brasil, é de ruptura e descontinuidade. Alexandre Shigunov Neto e Lizete Maciel concluem que, no Brasil, "não há uma continuidade nas propostas educacionais implantadas. A expulsão dos jesuítas e a total destruição de seu projeto educacional podem ser consideradas como o marco inicial dessa peculiaridade tão arraigada na Educação brasileira" (MACIEL; SHIGUNOV NETO, 2006: 472).

No entanto, mesmo que as reformas pombalinas para a educação não tenham alcançado o êxito que pretendiam, não se pode ignorar o impacto das aulas régias instituídas pelas reformas: os poucos estudantes que tiveram acesso às aulas régias, segundo Anita Almeida (2011:70), teriam sido os poucos a alcançarem, posteriormente, os bancos da Universidade de Coimbra. $\mathrm{O}$ novo sistema, portanto, marcou, ao menos, a trajetória desses homens.

Não se pode afirmar, contudo, que as escolas, a partir de então, tenham prontamente adotado uma postura laica em relação ao ensino, embora, certamente, tenham dado um passo importante em direção a essa característica que viria a ser primordial tanto na composição dos estados modernos como dos serviços que devem oferecer à população. Após a expulsão dos jesuítas e a implantação das aulas régias, outras congregações religiosas - beneditinos e franciscanos, principalmente - passaram a atuar como educadores. Desse modo, as funções de padre e professor estiveram, por muito tempo, amplamente associadas.

Organon, Porto Alegre, v. 29, n. 56, p. 223-244, jan/jun. 2014. 
A partir da chegada e instalação da família real portuguesa na colônia, a educação brasileira passou por novas transformações. A presença da corte portuguesa gerou uma demanda de certas especialidades e profissões inexistentes na colônia fosse criada, fazendo com que muitos investimentos fossem empreendidos na inauguração de novos cursos para suprir as novas necessidades.

Antes da chegada da família real, havia pouquíssimos médicos formados na colônia, sendo a falta de profissionais da área da saúde a motivação para a criação de diversos cursos de medicina. Portugal enfrentava a iminência da guerra contra Napoleão e precisava se estruturar belicamente para promover a defesa militar da Colônia. Para isso, criaram-se as Academias Militar e de Marinha, cujo objetivo era "a formação de hábeis oficiais de artilharia, de Engenharia, geógrafos e topógrafos com emprego administrativo nas minas, nos caminhos, portos, canais, pontes, fontes e calçadas, estabelecendo, dessa maneira, a Academia Real Militar" (BOAVENTURA, 2009: 134). Os currículos dos cursos das escolas militares contemplavam o ensino de disciplinas como a matemática e a física, mas negligenciavam completamente o estudo das Humanidades. Como exemplo, o currículo da Academia Militar do Largo de São Francisco, no Rio de Janeiro, era organizado da seguinte forma:

No $1^{\circ}$ ano, tinha Álgebra, Análise Geométrica, Trigonometria Retilínea e Desenho de Figura; no 2º Álgebra, Cálculo Diferencial e Integral e Geometria Descritiva; no $3^{\circ}$ o, Mecânica, Hidráulica e Desenho de Paisagem; no 4\% , Trigonometria Esférica, Ótica, Astronomia, Geodésia e Física; no 5², Tática, Fortificação de Campanha, Química, Filosofia Química e Desenho Militar; no 6 $6^{\circ}$, entravam Ataque e Defesa das Praças e Mineralogia; no sétimo, Artilharia, Zoologia, Desenhos e Máquinas de Guerra e outras matérias (BOAVENTURA, 2009: 134).

O ensino profissional também foi altamente valorizado e, além da instituição das cadeiras de Ciências Econômicas e de Química, foram criados a Aula de Comércio e o curso de Agricultura, em Salvador, na Bahia. O governo instituiu também as aulas de línguas vivas que consideravam úteis por suas diversas possibilidades de uso, como o Francês e o Inglês, e a Matemática passou a ocupar um lugar de maior destaque no currículo do ensino básico. Muitos esforços foram feitos durante esse período para suprir demandas educacionais há muito negligenciadas na colônia, mas,

Organon, Porto Alegre, v. 29, n. 56, p. 223-244, jan/jun. 2014. 
apesar dos diversos investimentos feitos, observa-se que poucos estavam relacionados ao ensino Humanista, que tinha sido o principal foco dos educadores até então. Nesse momento, o ensino das línguas clássicas começa um movimento de entrincheiramento, sendo, a princípio, reservado aos que decidiam, no ensino superior, por uma carreira voltada para as humanidades, e paulatinamente sumindo dos currículos gerais.

A partir da proclamação da república, outras necessidades surgiram: o estado passou a oferecer o ensino público e gratuito para uma quantidade maior de pessoas e a demanda por escolas e professores aumentou severamente. Intensificou-se o debate sobre a seleção cultural ideal para a composição do currículo da educação secundária no Brasil. Intelectuais e profissionais da educação passaram a debater com maior veemência sobre a legitimidade de um currículo humanista em confronto com a educação científica, que era cada vez mais valorizada. Os ataques aos ideais Humanistas presentes nos currículos se dirigiam com maior frequência para a questão da utilidade e necessidade dos estudos clássicos, do latim e do grego, embora todo o ensino de Humanidades estivesse sendo contestado (SOUZA, 2009: 73).

Souza (2009) demonstra como, a partir do início do século XX e ao longo de quarenta anos, as Humanidades batalharam por um espaço dentro dos currículos do ensino secundário, vindo uma das mais significativas derrotas através da supressão dos estudos clássicos, do latim e do grego dos currículos como matérias obrigatórias em 1961. O modelo humanista caíra em grande descrédito por parte de muitos educadores. Muitos defendiam que as mudanças nos currículos eram necessárias, pois a escola precisava se adaptar ao novo perfil do alunado, que via a escola como uma ponte para o mercado de trabalho.

Em 1942, com a reforma Capanema, que se consolidou através da Lei Orgânica do Ensino Secundário, os estudos clássicos ocuparam um lugar privilegiado no currículo: o ensino de Latim era destinado a todas as séries do curso ginasial, mas as ciências foram reservadas para as duas últimas séries do ciclo. Segundo Rosa Fátima de Souza, a reforma Capanema se configurou como "o último reduto da língua latina na educação secundária e da valorização da cultura geral como eixo central da formação da juventude" (SOUZA, 2009: 81). Mas esse currículo humanista e centrado nos estudos clássicos e no latim não durou muito tempo: a batalha entre o currículo humanista e científico continuou acirrada e a discussão sobre a democratização do ensino secundário motivou a problematização da finalidade de certas disciplinas nos currículos, que poderiam ser substituídas por outras, de cunho prático. O Humanismo clássico passou a ser repre- 
sentado como uma cultura de privilegiados que se opunha à expressão de uma sociedade democrática, postura que fez com que essas disciplinas ganhassem ainda mais descrédito dos educadores que discutiam as reformas necessárias para os currículos. Ainda segundo Souza,

O sincretismo entre o humanismo e os valores católicos foi muito além do uso da língua latina. (...) depois do século XVI, a civilização antiga foi assimilada por uma certa tradição cristã. Dessa maneira, o humanismo clássico atrelou-se de modo indissociável ao catolicismo (SOUZA, 2009, p. 84).

Essa associação entre catolicismo e estudos clássicos foi responsável tanto pela forte presença dessas disciplinas quando o domínio da Igreja sobre a educação era quase absoluto, como também pelo declínio das disciplinas no momento em que a Igreja perdia seu controle sobre as escolas e sobre a definição do currículo, uma vez que o Estado tendia para um processo de laicização, assim como os serviços por ele oferecidos. A discussão sobre a permanência dos estudos clássicos no currículo raramente se preocupou em redimensionar a maneira como essas disciplinas eram ministradas no ensino secundário, de modo que pudessem oferecer aos alunos maior contribuição em sua formação. A discussão esteve sempre ligada à questão "manter ou não manter". De fato, manter o antigo modelo não seria proveitoso para os currículos. A batalha pelo Humanismo, portanto, se configurava como uma luta entre um espírito de renovação e um espírito conservador. O desfecho dessa disputa se deu com a promulgação da Lei de Diretrizes e Bases da Educação Nacional em 1961 (Lei 4.024/61), que estabelecia novas diretrizes curriculares, instituindo sua diversificação e flexibilização, admitindo a presença de disciplinas obrigatórias, optativas e práticas educativas. Com essa reforma, o latim, o grego e os estudos clássicos se tornaram disciplinas optativas. Esse foi o golpe definitivo que levou os estudos clássicos a perderem a sua supremacia no ensino secundário, fazendo com que desaparecessem das práticas escolares. O latim se reduziu aos currículos das graduações e Licenciaturas em Letras e das graduações específicas em Latim.

No âmbito universitário, a supressão do latim e dos estudos clássicos dos currículos secundários também causou grande efeito: não havia mais a necessidade de formar professores de latim para a atuação no ensino secundário, uma vez que a demanda havia diminuído drasticamente. Também nos currículos dos cursos superiores o latim e os estudos clássicos perderam seu lugar cativo. Disciplinas como a linguística, que se desenvolviam cada vez

Organon, Porto Alegre, v. 29, n. 56, p. 223-244, jan/jun. 2014. 
mais, ocupavam espaços antes destinados aos estudos clássicos. O latim se reduziu a dois semestres, quando muito, nos currículos universitários.

As décadas de 1980 e 1990 do século XX foram o momento de retomada para um grupo de professores ligados aos estudos clássicos no Brasil. Tendo sobrevivido de alguma forma a esses cortes extremos, a disciplina sobreviveu, ainda que em geral apenas sob a forma de língua latina, nos currículos de Letras e de alguns outros cursos de Humanas. Aos poucos, a área começou a se reformular: muitas influências das teorias modernas da literatura e da linguagem repercutiram positivamente na área de estudos clássicos. $\mathrm{O}$ ensino de latim na universidade também passou a ser discutido, o que levou muitos professores a revisarem seus métodos. Apesar de discutir uma realidade estrangeira, as reflexões de Pearcy (2010) a respeito do ensino de latim nos colégios e universidades vêm a propósito daquele momento no ensino do latim, mesmo em nossa realidade nacional. $\mathrm{O}$ autor aponta para a existência de duas tradições de ensino antagônicas, que ele explica em termos de um conflito entre o Humanismo e a filologia. De um lado, há aqueles que defendem o latim como filologia e os métodos focados em traduções e análises gramaticais. De outro, há os que enxergam o latim como uma língua e valorizam a utilização de métodos que incentivem o uso do idioma "como uma língua", patrimônio da antiguidade. Pearcy aponta, acertadamente, que os professores de latim lecionam diante de uma tensão entre essas duas tradições (liberal e humanista em oposição à filológica). O mesmo ocorreu (e ainda ocorre) no Brasil, com os estudos de latim conduzidos em diferentes pontos dessa escala que vai da filologia ao humanismo, com maior ou menor consciência e reflexão sobre a própria prática docente. Charlene Miotti (2004), focando a discussão no contexto brasileiro, identifica essas mesmas questões, além de alguns questionamentos sobre a forma de condução dos cursos de latim para as turmas de graduação em Letras no Brasil, sobretudo em São Paulo.

O texto de Miotti, porém, já integra um novo momento na prática do ensino de língua latina no Brasil, não só pelo interesse renovado em discutir a questão como no ímpeto em se fazer do ensino de latim objeto de pesquisa. A mesma autora aponta, no mesmo texto, que a área de ensino de latim, no Brasil, necessitava de maior número de pesquisas especializadas, que buscassem apresentar soluções para os diversos problemas da área, tais como alto número de evasão dos alunos nas disciplinas de latim. $\mathrm{O}$ fato de que esse trabalho e outros de mesmo teor começam a serem publicados, a partir de fins da década de 1990, clamando por mais trabalhos, já é fruto de uma mudança de formas e paradigmas do ensino de latim no Brasil. 
Após Miotti, Barboza (2007) elaborou uma descrição de pontos de vista e propostas de ensino expostas em prefácios de manuais de ensino de latim, tendo selecionado autores do início e do fim do século XX.

Já em artigo de 2009, Samantha de Moura Maranhão, procura refletir sobre a inclusão das disciplinas de língua latina nas grades curriculares dos cursos de Letras modernas. Em seu artigo, a autora tece uma crítica à forma como o latim tem sido ensinado nas disciplinas obrigatórias, pois um curto espaço de tempo é reservado para o ensino superficial de estruturas morfossintáticas e exercícios de memorização de vocabulário, procedimentos que apresentam resultados ineficazes (MARANHÃO, 2009: 30).

As três autoras trazem para as suas discussões elementos centrais do atual panorama do ensino de latim no Brasil: as poucas horas nos currículos de graduação em Letras; o objetivo de familiarizar os alunos com a língua latina, de forma a resgatar a relevância cultural do latim, destacando a importância e benefícios adquiridos pelos alunos que podem acessar os textos produzidos por autores clássicos; a ineficácia de métodos do tipo filológico ou gramatical-tradutório para o alcance desses objetivos; a busca pelo uso de conhecimentos novos, trazidos em especial da Linguística Aplicada, de forma a otimizar as horas em sala de aula e facilitar o aprendizado ${ }^{7}$.

Estes e outros trabalhos semelhantes, surgidos durante a primeira década do século XXI, chegam em geral à conclusão de que a carga horária obrigatória destinada ao ensino de latim é insuficiente; de que as ementas das disciplinas deveriam contemplar tópicos linguísticos e culturais; de que o latim deve ser visto como uma língua estrangeira e seu aprendizado deve considerar o "desenvolvimento da habilidade de refletir a língua como fenômeno social, histórico, cultural, político e ideológico, dentre outros" (MARANHÃO, 2009: 33); de que o ensino de latim da forma como ele chegou ao século XXI é insatisfatório para professores e alunos, e que precisa urgentemente ser melhor estudado, compreendido e reformulado ${ }^{8}$.

Esta pesquisa, da qual aqui apresentamos os primeiros resultados, surgiu a partir dessas conclusões um tanto depressivas desses trabalhos, mas também da observação de que, ainda que se apontassem com frequência

7 Não nos detivemos aqui na discussão sobre as metodologias de ensino de latim, seus objetivos e sua história, para que não nos desviássemos do foco deste trabalho. Este assunto é abordado em LEITE, Leni Ribeiro. Aprendendo a ler - e a falar - em latim. In: PRATA, Patrícia \& FORTES, Fábio da Silva. O Latim Hoje. No prelo, publicação prevista para 2014.

8 Em especial, chamamos a atenção para o trabalho de Miotti (2006), não só por seu maior fôlego mas por apresentar conclusões embasadas em questionários realizados com professores de universidades públicas, ainda que seu escopo tenha sido apenas o estado de São Paulo.

Organon, Porto Alegre, v. 29, n. 56, p. 223-244, jan/jun. 2014. 
os problemas, e aqui e ali se acenassem algumas sugestões de solução, faltava uma abordagem mais ampla nacionalmente e que levasse em conta não só as dificuldades reais mas também os desejos dos profissionais que enfrentam essas dificuldades em seus cotidianos. A realização recente dos três Encontros de Professores de Latim ${ }^{9}$ - e as distâncias percorridas por seus participantes para que estivessem presentes a essas discussões - nos levaram a crer que seria possível contar com a participação de ao menos alguns desses professores em um esforço de levantamento de dados não só sobre como o latim é ensinado como também sobre alguns dos pressupostos que sustentam as práticas e sobre o que desejam estes profissionais para as suas práticas.

Dispusemo-nos, assim, a criar um banco de dados, com o intuito de traçar um panorama, o mais completo possível, acerca do ensino de latim nas universidades públicas brasileiras. Durante os próprios Encontros de Professores de Latim, observamos que:

a) há, no Brasil, dez universidades que oferecem a graduação plena (bacharelado e/ou licenciatura) em Língua e Literatura Latina UFRGS, UFPR, USP, Unesp, UFRJ, UERJ, UFF, UFMG, UFJF, $\mathrm{UFBA}^{10}$.

b) há duas universidades que oferecem graduação plena em Línguas Clássicas - UFC e UFPB.

c) há um número muito maior de universidades públicas brasileiras que têm professores de latim e oferecem disciplinas de língua, literatura e/ou cultura latina de forma regular a seus alunos. A realidade destas últimas, apesar de bastante variada, responde de fato pela maior fatia de alunos de latim no país, ainda que estes, em sua grande maioria, não tenham um contato muito longo com a língua e nem venham a fazer dela seu centro de estudo, com bem-vindas e importantes exceções.

Observamos, ainda, durante os Encontros e em conversas com outros colegas, que o grau de descontentamento e isolamento dos professores de latim que viviam a realidade expressa pelo grupo $\mathrm{C}$ era muito grande, $\mathrm{e}$, principalmente, que este grupo era quase invisível frente ao grupo que se

9 Ocorridos em 2010 (UFJF), 2011 (Unicamp) e 2012 (UFF), organizados pelo Grupo de Pesquisa Ensino de Latim, cadastrado na plataforma do CNPq, cujos líderes são Patrícia Prata (Unicamp) e Fábio da Silva Fortes (UFJF). Para mais informações sobre os encontros, v. https://sites.google. com/site/encontrodeprofessoresdelatim/, acesso em 15 de março de 2013.

10Essas informações foram colhidas também no banco de dados oficial do Ministério da Educação: http://e-mec.mec.gov.br. 
dedica à docência dos alunos "específicos", dada a falta de discussões, materiais e soluções apresentadas para as suas dificuldades. Observamos também a peculiaridade de seu público, o questionamento constante a que se veem sujeitados acerca da utilidade e importância do latim dentro dos currículos de línguas modernas e, principalmente, a necessidade de parâmetros e formatos que os auxiliem a estabelecer sua prática docente. Nota-se ainda que esta situação é mais grave para professores de universidades fora do eixo Sul-Sudeste, onde se concentram a maior parte das instituições com cursos específicos de Latim ou de Letras Clássicas, e de universidades geograficamente distantes dos grandes centros.

Tendo isso em vista, voltamos o escopo de nossa pesquisa para este grupo, em especial para o relacionamento com a maior fatia do seu alunado, ou seja, aqueles alunos que devem ou desejam estudar latim mas que não terão quatro ou mais anos de contato com a língua. Assim, após o levantamento numérico, passamos a um levantamento de dados mais específico, que buscava entender de que maneira o latim, sua literatura e cultura, ocupam papéis dentro da formação dos alunos de Letras Modernas. Assim, contatamos professores, coordenadores, chefes de Departamento e outros que nos pudessem oferecer informações acerca do número de disciplinas, dos cursos, dos professores e das ementas. A partir daí, buscamos ouvir os professores de latim a respeito de vários temas ligados a suas práticas em sala de aula, tais como as disposições ideais das disciplinas ligadas aos estudos clássicos nos currículos das graduações em Letras acerca da obrigatoriedade do ensino de língua ou de literatura clássica; se os estudos clássicos constam ou deveriam constar entre as disciplinas optativas; dentre outras interrogações que nos surgiram ou foram propostas pelos próprios professores. Um questionário foi elaborado com o objetivo de investigar a situação do latim e a prática dos docentes e seus pensamentos sobre a oferta ideal das disciplinas de estudos clássicos nos currículos de Letras e enviado para ao menos um professor de cada universidade pública brasileira cujo contato nos foi possível conseguir. Por fim, passamos à análise de cada questionário respondido em busca de oferecer um panorama inicial sobre o ensino de latim nas universidades públicas brasileiras do século XXI.

O questionário apresentava seis questões amplas, e recebemos para elas respostas curtas e longas, de acordo com o desejo de cada entrevistado. As perguntas eram as que se seguem:

1.O latim faz parte do currículo obrigatório dos cursos de Licenciatura e Bacharelado em Letras da sua instituição? De que maneira e em quantos semestres a disciplina é ofertada?

Organon, Porto Alegre, v. 29, n. 56, p. 223-244, jan/jun. 2014. 
2.Qual a ementa programada pela sua instituição para as disciplinas de latim para os cursos de Licenciatura e Bacharelado em Letras?

3.Quais métodos e materiais você utiliza para ministrar suas aulas de latim para alunos dos cursos de Licenciatura e Bacharelado em Letras da sua instituição?

4. Você trabalha textos literários ou outros tópicos culturais nas aulas de latim?

5.Há oferta de disciplinas optativas de língua ou literatura latina em sua instituição? Com que frequência essas disciplinas são ofertadas e qual a média de alunos matriculados?

6.Para você, qual seria a disposição e oferta ideais de língua, literatura e cultura latina nos currículos dos cursos de Licenciatura e Bacharelado em Letras, considerando a formação do aluno que não prosseguirá pesquisa e aprofundamento em Estudos Clássi$\cos$ ?

Para esta primeira etapa de pesquisa, obtivemos resposta de dezessete universidades ${ }^{11}$, assim distribuídas geograficamente:

a) Da região Sul: UFRGS, UFPR.

b) Da região Sudeste: UFMG, Ufop, UFJF, UFV, Unifal, Usp, Unesp, Unicamp, UFRJ, UFF.

c) Da região Centro-Oeste: UnB.

d) Da região Nordeste: UFBA, UFPI, UFRN.

e) Da região Norte: UFPA.

Apresentamos a seguir alguns dados interessantes colhidos nesta fase da pesquisa:

a) Das dezessete universidades que participaram da pesquisa, observamos que apenas uma não possui disciplinas de Língua, Literatura ou Cultura Clássica entre as obrigatórias dos cursos de Licenciatura ou Bacharelado em Letras Modernas - a UFMG.

b) Quatorze universidades possuem disciplinas de Língua Latina obrigatórias nos currículos dos cursos de Licenciatura ou Bacharelado em Letras, mas apenas oito universidades apresentam disciplinas obrigatórias de Literatura ou Cultura Clássica nos currículos.

11Quando este texto já estava em fase avançada de elaboração, recebemos mais respostas (UfPel, Ufes, UEA, UFPB, UFG, UEPG, Unifesp, UEFS), que elevaram o número de instituições representadas para vinte e cinco. Estas respostas serão incorporadas em próximas etapas da pesquisa. 
c) Apenas uma universidade apresenta disciplinas obrigatórias de Literatura ou Cultura Clássica sem apresentar disciplinas obrigatórias de Língua Latina - a Ufop.

d) Entre as universidades que apresentam tanto disciplinas de Língua como de Literatura e Cultura no currículo obrigatório dos cursos de Licenciatura e Bacharelado em Letras, quase todas oferecem igual número de disciplinas de Literatura e Língua, exceto duas; destas, uma oferta duas disciplinas de Língua e uma disciplina de Literatura e Cultura, enquanto a outra oferta uma disciplina de Língua e duas disciplinas de Literatura e Cultura.

e) Entre as dezessete universidades que ofereceram dados, sete possuem graduação específica em Latim, podendo oferecer aos alunos das outras graduações em Letras diversas disciplinas optativas, que são obrigatórias para as habilitações específicas. As outras universidades, que não possuem graduação específica, tendem a ter uma oferta bem menos frequente de optativas na área de Estudos Clássicos, pois o quadro de professores é reduzido e deve atender as disciplinas obrigatórias, além de se envolver com pesquisa e pós-graduação, evidenciando um dos problemas já apontados anteriormente.

f) Com exceção de uma universidade, que oferece todas as disciplinas de Estudos Clássicos como optativas para as habilitações em Letras, todas as universidades que apresentam graduação em Latim oferecem disciplinas obrigatórias de Literatura ou Cultura Latina para os cursos de Letras Modernas.

g) Ao responderem à sexta questão, que procura identificar qual a disposição ideal do Latim e dos Estudos Clássicos nos currículos das graduações em Letras, considerando a formação dos alunos que não prosseguirão o aprofundamento nos Estudos Clássicos, pudemos observar que os professores, em sua maioria, consideraram importante a inclusão ou aumento do número de disciplinas específicas de Literatura e Cultura Clássica - que não incluíssem o estudo de Língua - nos currículos obrigatórios.

Há, certamente, muitas outras observações interessantes a se fazerem com base nas respostas que nos foram oferecidas pelos professores de Latim, e esta pesquisa pretende prosseguir, não só coletando mais questionários mas também através de uma segunda etapa, de entrevistas a alguns professores, que tem como objetivo aprofundar esse panorama do ensino 
de Latim nas universidades brasileiras, além de tentativamente traçar um perfil ideal, segundo os profissionais da área, do papel do ensino de latim na formação dos alunos de Letras. Numa terceira etapa, após termos respondido as questões sobre por quem, onde e para que o latim vem sendo ensinado em nossas instituições de ensino superior, passaremos à importante indagação do como, que, levemente abordada na pergunta de número três do questionário, merece ser trabalhada com mais vagar.

À guisa de conclusão, gostaríamos de apresentar um posicionamento extraído das respostas que recebemos para os questionários e que reflete uma mudança fundamental de mentalidade no que diz respeito ao ensino de Latim. Este novo posicionamento é fruto do questionamento e por fim da negação do objetivo do estudo do latim como "supralíngua" ou ferramenta para melhor compreender o português ou outras línguas modernas, uma afirmação bastante frequente nos manuais de ensino dos séculos XIX e XX, tais como os de Milton Valente ou de Ernesto Faria por exemplo (BARBOZA, 2007: 45-6; SOUZA, 2009: 75), e comum nos corredores das universidades brasileiras até bem pouco tempo. Essa reflexão e alteração de paradigma, que não entende mais o estudo de latim como passo necessário para o conhecimento pleno de línguas modernas, fez com que se redimensionasse a percepção da importância da disciplina nos currículos de Letras. Reforçou-se cada vez mais a compreensão do Latim não como sistema ou arqueologia das línguas modernas, mas como língua em $\mathrm{si}^{12}$, que possibilita o acesso a um grandioso patrimônio cultural produzido tanto no antigo mundo romano - durante o período em que o latim era língua nativa - como em períodos posteriores, quando o latim se tornou língua de cultura e comunicação entre a elite intelectual europeia. De que maneira, portanto, a disciplina contribui de modo efetivo para a formação dos alunos de graduação em Letras Modernas? A resposta mais comum atualmente é a de que o intenso diálogo entre a literatura moderna e a literatura clássica não pode ser ignorado, pois a importância do latim, para um grande número de professores, parece se dever ao fato de que essa língua é parte de um patrimônio cultural que está na raiz da formação das sociedades ocidentais e que guiou a tradição literária europeia até o século XVIII. Ou seja, os estudos de Literatura e Cultura Clássicas ganham proeminência e importância aos olhos dos profissionais da área como justificativa para a sua presença no currículo - e não mais a língua, cuja importância agora é a de veículo para que se alcance aquele arcabouço, e não de fim em si mesma.

12Essa discussão foi levada a cabo e resolvida em muitos artigos nacionais e estrangeiros, dentre os quais o de FORTES (2010). 
Uma formação do aluno de Letras que não passe pela literatura e cultura produzidas nos antigos mundos grego e romano é deficiente e lacunar. A inclusão de mais disciplinas voltadas para a literatura e a cultura clássica se configura, ao menos na voz dos nossos entrevistados, como uma tentativa de oferecer ao aluno uma base mais sólida sobre essa cultura, visto que o estudo da língua latina, somente, não é capaz de transmitir todas as referências importantes sobre o mundo antigo para os alunos de letras. No sentir dos profissionais de língua e literatura latina do século XXI, a língua não deve mais ser estudada sem a presença constante do patrimônio cultural do qual ela é transmissora, pois é ele quem justifica o seu estudo e sobrevivência.

\section{BIBLIOGRAFIA}

ALMEIDA, Anita Correia Lima de. Aulas Régias no Império Colonial Português: o global e o local. In: LIMA, Ivana Stolze; CARMO, Laura do (Org.). História social da língua nacional. Rio de Janeiro: Casa de Rui Barbosa, 2008. p. 65-90

BANGERT, William V. História da Companhia de Jesus. São Paulo: Loyola, 1985.

BARBOZA, Gabriela. Reflexões sobre abordagens e manuais de ensino de latim. Ideias. Revista do Curso de Letras. Santa Maria, n. 24, p. 4449, jul/dez 2007.

BOAVENTURA, Edivaldo M. A educação brasileira no período Joanino. In: ___ . A construção da universidade baiana: objetivos, missões e afrodescendência. Salvador: EDUFBA, 2009, p. 129-141.

FORTES, Fábio da Silva. A "língua" e os textos: gramática e tradição no ensino de latim. Instrumento, Juiz de Fora, v.12, n.1, p.63-70, jan/jun 2010.

FRANCA, L. O método pedagógico dos jesuítas: o Ratio Studiorum. Rio de Janeiro: Agir, 1952.

FREIRE, Luiz GL. Educação Jesuítica do século XVI ao XVIII: a memória do espaço e o espaço da memória. Cadernos do CEOM, Chapecó, v. 22, n.31, p. 177-191, 2009.

IJSEWIJN, Jozef. A Companion to Neo-Latin Studies. Volume 1: History and Diffusion of Neo-Latin Literature. 2.ed. rev. Louvain: Leuven University; Peeters, 1990. IJSEWIJN, Jozef \& SACRÉ, Dirk. A Companion to Neo-Latin Studies. Volume 2: Literary, Linguistic, Philological and Editorial Questions. 2.ed. rev. Louvain: Leuven University, 1998.

Organon, Porto Alegre, v. 29, n. 56, p. 223-244, jan/jun. 2014. 
MACIEL, Lizete S.B.; SHIGUNOV NETO, Alexandre. A educação brasileira no período pombalino: uma análise histórica das reformas pombalinas do ensino. Educação e Pesquisa, São Paulo, v.32, n.3, p. 465-476, set./dez. 2006. MARANHÃO, Samantha de Moura. Reflexões sobre ensino de língua latina em cursos superiores de Letras modernas. Instrumento, Juiz de Fora, v. 11, n. 1, p. 27-36, jan/jun 2009.

MIOTTI, Charlene Martins. Universidades Estaduais Paulistas: o latim na berlinda. Anais do $6^{\circ}$ Encontro Celsul - Círculo de Estudos Linguísticos do Sul, novembro de 2004. Disponível em: <http://celsul.org.br/ Encontros/06/Individuais/182.pdf>. Acesso em 15 de março de 2013. MIOTTI, Charlene Martins. O ensino do latim nas universidades públicas do estado de São Paulo e o método inglês Reading Latin: um estudo de caso. 2006. Dissertação (Mestrado em Linguística). Instituto de Estudos da Linguagem (IEL), Unicamp, Campinas, 2006.

OSTLER, Nicholas. Ad infinitum: a biography of Latin. New York: Walker, 2007. PEARCY, T. Lee. Preparing Classicists or Preparing Humanists? Teaching Classical Languages. Spring: 2010, p. 192-195. Disponível em: <http://tcl. camws.org/spring2010/ TCL_I_ii_Spring_2010.pdf >. Acesso em 15 de março de 2013.

PEDRO, Lívia. História da Companhia de Jesus no Brasil: Biografia de uma obra. 2008. Dissertação (Mestrado em História). Universidade Federal da Bahia, Salvador, 2008.

RAYMUNDO, Gislene Miotto Catolino. Os princípios da modernidade nas práticas educativas dos jesuítas. 1998. 143p. Dissertação (Mestrado em Educação). Universidade Estadual de Maringá, Maringá, 1998.

SHIGUNOV NETO, Alexandre; MACIEL, Lizete S.B. O ensino jesuítico no período colonial brasileiro: algumas discussões. Educar. Curitiba, n. 31, p. 169-189, 2008.

SOLODOW, Joseph B. Latin alive: the survival of Latin in English and the Romance languages. Cambridge: Cambridge University, 2010.

SOUZA, Rosa Fátima de. A renovação do currículo do ensino secundário no Brasil: as últimas batalhas pelo humanismo (1920-1960). Currículo sem Fronteiras, v.9, n.1, pp.72-90, Jan/Jun 2009.

VERNEY, Luís António. Verdadeiro método de estudar. Edição organizada por António Salgado Júnior. Lisboa: Sá da Costa, 1949-1953.

Recebido em: 13/11/2013. Aceito em: 21/03/2014 